\title{
Does Chronic Kidney Disease Result in High Risk of Atrial Fibrillation?
}

\author{
Dapeng Zhang ${ }^{1}$, Yibin Feng ${ }^{2}$, Feona Chung-Yin Leung ${ }^{2}$, Lingchong Wang ${ }^{3 *}$ and \\ Zhimin Zhang ${ }^{1 *}$
}

\begin{abstract}
'Department of Chinese Medicine, The First Affiliated Hospital of Guangzhou Medical University, Guangzhou, China, ${ }^{2}$ Li Ka Shing (LKS) Faculty of Medicine, School of Chinese Medicine, The University of Hong Kong, Hong Kong, China, ${ }^{3}$ School of Pharmacy, Nanjing University of Chinese Medicine, Nanjing, China
\end{abstract}

Keywords: chronic kidney disease, atrial fibrillation, hypertension, renin-angiotensin-aldosterone system, atrial structural remodeling

OPEN ACCESS

Edited by:

Teresa Seccia,

University of Padova, Italy

Reviewed by:

Marco Proietti,

University of Birmingham,

United Kingdom

*Correspondence:

Lingchong Wang

993wic@njucm.edu.cn

Zhimin Zhang

zhangzhimin51666@163.com

Specialty section

This article was submitted to

Cardiac Rhythmology,

a section of the journal

Frontiers in Cardiovascular Medicine

Received: 28 March 2019

Accepted: 03 June 2019

Published: 20 June 2019

Citation:

Zhang $D$, Feng $Y$, Leung FC-Y, Wang $L$ and Zhang $Z$ (2019) Does Chronic Kidney Disease Result in High Risk of Atrial Fibrillation?

Front. Cardiovasc. Med. 6:82. doi: 10.3389/fcvm.2019.00082
Chronic kidney disease (CKD), defined as either pathological albuminuria $(>30 \mathrm{mg} / 24 \mathrm{~h})$ or decreased GFR $\left(<60 \mathrm{~mL} / \mathrm{min} / 1.73 \mathrm{~m}^{2}\right)$, is associated with an increase in cardiovascular morbidity and mortality $(1,2)$. Atrial fibrillation (AF), the most common sustained arrhythmia associated with increased risk of ischaemic and haemorrhagic stroke, is increasingly prevalent with the decline of kidney function (3). It was reported that the occurrence risk of AF began to grow as renal dysfunction deteriorated $(\mathrm{CKD}$ at stage $3: \mathrm{HR}=1.6,95 \% \mathrm{CI}=1.27-2.13$; at stage 4 : $\mathrm{HR}=3.2$, $95 \% \mathrm{CI}=2.0-5.0)$ (4). Similar results from a Medicare cohort pointed out that CKD increases the 2 -year incidence of AF to $12.2 \%$ at stages 1 and 2, and to $14.4 \%$ at stages 3-5, compared with $7.5 \%$ for patients without CKD (5). Although the incidence of AF in hypertensive patients with CKD is significantly increased (adjusted $\mathrm{HR}=2.18,95 \% \mathrm{CI}$ : 1.2-3.9), it could be independently increased in advanced CKD (stage 4/5) patients (6). On the contrary, the improvement of kidney function could help reduce the recurrence of $\mathrm{AF}$ in patients undergoing catheter ablation for $\mathrm{AF}$ (7).

$\mathrm{CKD}$ and $\mathrm{AF}$ share several common predisposing factors including hypertension, heart failure, coronary artery disease, obesity, and diabetes, etc (8). CKD activates the renin-angiotensin-aldosterone system (RAAS) and sympathetic nervous system and induces oxidative stress, systemic inflammation, and volume overload (8). These factors are highly correlated with atrial electrical and structural remodeling, contributing to the promotion and perpetuation of AF. The atrial electrical remodeling refers to the changes in electrical dysfunction influenced by the ion channels, the disequilibrium of intracellular $\mathrm{Ca}^{2+}$ homeostasis and gap junctions (9), and atrial structural remodeling includes atrial enlargement, cardiomyocytes hypertrophy, and interstitial fibrosis (10). Much evidence indicates that the chronic intra-atrial or intra-ventricular volume overload and the activation of RAAS and SNS resulting from CKD could urge stress relative signaling pathways [e.g., tumor necrosis factor- $\alpha$, transforming growth factor- $\beta 1$ (TGF- $\beta 1$ ), and NAPDH oxidases, etc.], leading to myocyte apoptosis, interstitial fibrosis and the alteration of electrical activity (8). Besides, the enhanced RAAS could act synergistically with oxidative stress and inflammatory regulators such as TGF $\beta 1$ and NLR (nucleotide-binding domain leucine-rich repeat-containing receptor) pyrin domain-containing protein 3 (NLRP3) inflammasome to promote atrial structural remodeling and $\operatorname{AF}$ eventually $(11,12)$. Atrial connexins play an important role in maintaining the homogeneity of atrial electrical conduction and are easy to be influenced by the activation of inflammation and oxidative stress and the atrial structural remodeling (11). Therefore, the occurrence and development of atrial fibrillation with CKD could be multifactorial and multi-targets and Figure 1 presents the mechanism pattern of AF occurrence in CKD.

The coexistence of $\mathrm{CKD}$ and $\mathrm{AF}$ can present a challenge for treatment. Renal dysfunction increases the risk of bleeding and complications from anti-arrhythmic drugs of which are eliminated by kidney when patients are under anticoagulation and rate control $(12,13)$. Unfortunately, current (drug) therapies for $\mathrm{AF}$ are palliative due to the high rate of recurrence 


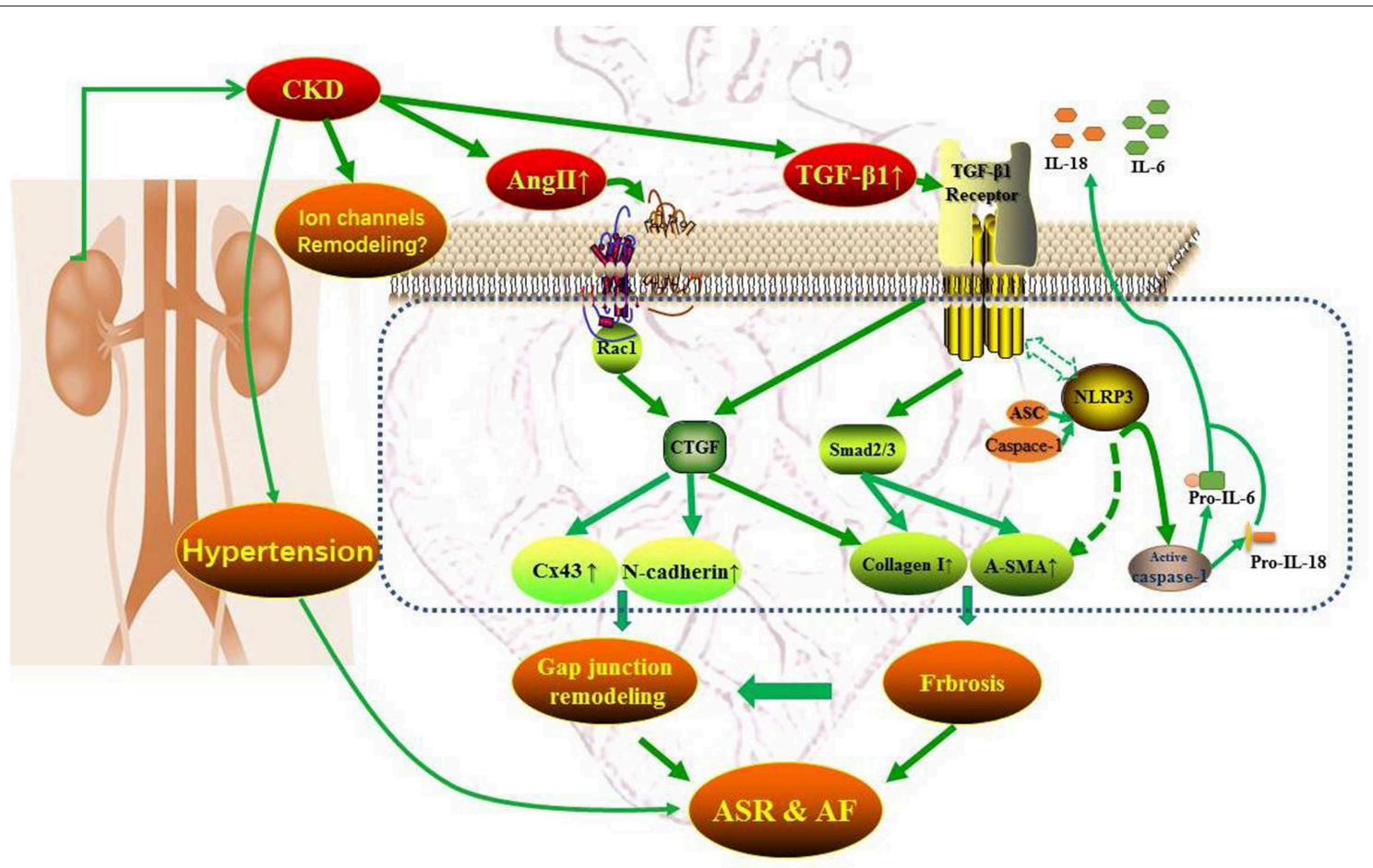

FIGURE 1 | Mechanism pattern diagram of AF occurrence in CKD.

even excluding CKD (14). The strategies for AF therapies have been changing continuously from treatment to preventionthe upstream therapy for AF which is proposed to prevent AF development by inhibiting atrial remodeling including atrial structural and electrical remodeling $(14,15)$. For the existing difficulties in comprehensive treatment for both diseases, to prevent the prevalence of $\mathrm{AF}$ in $\mathrm{CKD}$ patients should be considered as one part of the upstream therapies for AF.

In the paper published in current issue of Frontiers, Qiu et al. showed that CKD resulted in left atrial enlargement, interstitial fibrosis, and increased AF inducibility, which may be related to the activation of TGF- $\beta 1 /$ Smads and NLRP3 inflammasome signaling as well as connexins remodeling (16). These findings revealed that the pathologic features of $\mathrm{CKD}$ enhanced AF are multiplex and suggested several potential mediators of increased AF prevalence in CKD. The present study focused mainly on the atrial structural remodeling, including interstitial fibrosis and left atrial enlargement and the morphologic changes of electrocardiogram including $\mathrm{P}$ waves and $\mathrm{PR}$ interval. In combination with previous findings, the present study also identified CTGF and Rac-1 as the potential mediators of atrial structural remodeling (ASR). Most importantly, since the molecular mechanisms of the activations of TGF- $\beta 1 /$ Smads, NLRP3 inflammasome, CTGF and Rac-1, and connexins remodeling all links to an increased angiotensin II, we can propose that a potential anti-AF approach for targeting the atrial structural remodeling by using angiotensin II antagonists is available to prevent $\mathrm{AF}$ in patients with CKD. Indeed, the main components of the RAAS, angiotensin II, is up-regulated in both AF patients and animals with CKD. However, the benefits of RAAS inhibition by angiotensin converting enzyme inhibitors or angiotensin receptor blockers with respect to the prevention of $\mathrm{CKD}$ induced AF have not been fully investigated. Therefore, the present study provides potential mediators involved in atrial structural remodeling, which may be constituted a promising option for the development of therapeutic strategy for AF upstream therapy.

However, the present study has several unfinished works and caveats. The features of atrial electrical remodeling in a CKD setting still remain unclear. The present study didn't mention any alterations related to the possible remodeling of ion channels, which is very likely to occur in this model. The findings of connexins remodeling and the morphological changes of $\mathrm{P}$ waves are far from adequate to elucidate the atrial electrical remodeling. Besides, it is important to investigate the functional changes of connexins beyond its alterations in protein expression and distribution and to ascertain whether the alterations of atrial connexins are cause or coincidence of $\mathrm{AF}$ in patients with $\mathrm{CKD}$. Hypertension as a cause and consequence of $\mathrm{CKD}$ is also a strong risk factor for developing AF. In the present study, they didn't rule out the arrhythmogenic potential from hypertension. Additionally, a deeper interpretation of these molecular targets that contribute to atrial structural remodeling under CKD condition is needed. Regardless of these limitations, it is very 
encouraging to establish such an animal model and to investigate interdisciplinary research.

\section{AUTHOR CONTRIBUTIONS}

$\mathrm{DZ}$ and $\mathrm{ZZ}$ conceived and designed this research. LW, YF, and FL provided materials for writing this manuscript. DZ and LW wrote the manuscript.

\section{REFERENCES}

1. Herzog CA, Asinger RW, Berger AK, Charytan DM, Diez J, Hart RG, et al. Cardiovascular disease in chronic kidney disease. A clinical update from Kidney Disease: Improving Global Outcomes (KDIGO) Kidney Int. (2011) 80:572-86. doi: 10.1038/ki.2011.223

2. Mark PB. Strategies to manage cardiovascular risk in chronic kidney disease. Nephrol Dial Transplant. (2018) 33:23-5. doi: 10.1093/ndt/gfx329

3. Soliman EZ, Prineas RJ, Go AS, Xie DW, Lash JP, Rahman M, et al. Chronic kidney disease and prevalent atrial fibrillation: the Chronic Renal Insufficiency Cohort (CRIC). Am Heart J. (2010) 159:1102-7. doi: 10.1016/j.ahj.2010.03.027

4. Alonso A, Lopez FL, Matsushita K, Loehr LR, Agarwal SK, Chen LY, et al. Chronic kidney disease is associated with the incidence of atrial fibrillation the Atherosclerosis Risk in Communities (ARIC) study. Circulation. (2011) 123:2946-81. doi: 10.1161/CIRCULATIONAHA.111.020982

5. Nelson SE, Shroff GR, Li SL, Herzog CA. Impact of chronic kidney disease on risk of incident atrial fibrillation and subsequent survival in medicare patients. J Am Heart Assoc. (2012) 1:1-10. doi: 10.1161/JAHA.112.002097

6. Horio T, Iwashima Y, Kamide K, Tokudome T, Yoshihara F, Nakamura S, et al. Chronic kidney disease as an independent risk factor for new-onset atrial fibrillation in hypertensive patients. J Hypertens. (2010) 28:1738-44. doi: 10.1097/HJH.0b013e32833a7dfe

7. Navaravong L, Barakat M, Burgon N, Mahnkopf C, Koopmann M, Ranjan $\mathrm{R}$, et al. Improvement in estimated glomerular filtration rate in patients with chronic kidney disease undergoing catheter ablation for atrial fibrillation. $J$ Cardiovasc Electrophysiol. (2015) 26:21-7. doi: 10.1111/jce.12530

8. Voroneanu L, Ortiz A, Nistor I, Covic A. Atrial fibrillation in chronic kidney disease. Eur J Intern Med. (2016) 33:3-13. doi: 10.1016/j.ejim.2016. 04.007

9. Everett TH, Olgin JE. Basic mechanisms of atrial fibrillation. Cardiol Clin. (2004) 22:9-20. doi: 10.1016/S0733-8651(03)00117-6

10. Everett TH, Olgin JE. Atrial fibrosis and the mechanisms of atrial fibrillation. Heart Rhythm. (2007) 4:S24-7. doi: 10.1016/j.hrthm.2006.12.040

11. Adam O, Lavall D, Theobald K, Hohl M, Grube M, Ameling S, et al. Racl-induced connective tissue growth factor regulates connexin 43 and

\section{ACKNOWLEDGMENTS}

The financial grant of this work has been sponsored by the Jiangsu Overseas Visiting Scholar Program for University Prominent Young \& Middle-aged Teachers and Presidents in 2018 (Approved No. [2018]4156) and the Talent Upgrading Project form Construction of High-level Universities in Guangzhou city.

N-cadherin expression in atrial fibrillation. J Am Coll Cardiol. (2010) 55:46980. doi: 10.1016/j.jacc.2009.08.064

12. Chen G, Chelu MG, Dobrev D, Li N. Cardiomyocyte inflammasome signaling in cardiomyopathies and atrial fibrillation: mechanisms and potential therapeutic implications. Front Physiol. (2018) 9:1115. doi: $10.3389 /$ fphys.2018.01115

13. Lip GYH, Frison L, Grind M, Invest S. Angiotensin converting enzyme inhibitor and angiotensin receptor blockade use in relation to outcomes in anticoagulated patients with atrial fibrillation. J Intern Med. (2007) 261:57786. doi: 10.1111/j.1365-2796.2007.01780.x

14. Poli D, Antonucci E, Zanazzi M, Grifoni E, Testa S, Ageno W, et al. Impact of glomerular filtration estimate on bleeding risk in very old patients treated with vitamin $\mathrm{K}$ antagonists Results of EPICA study on the behalf of FCSA (Italian Federation of Anticoagulation Clinics). Thromb Haemost. (2012) 107:1100-6. doi: 10.1160/TH11-10-0721

15. Camm AJ, Kirchhof P, Lip GYH, Schotten U, Savelieva I, Ernst S, et al. Guidelines for the management of atrial fibrillation The Task Force for the Management of Atrial Fibrillation of the European Society of Cardiology (ESC). Europace. (2010) 12:1360-420. doi: 10.1093/eurheartj/ehq278

16. Qiu HL, Ji CL, Liu W, Wu YC, Lu ZY, Lin QZ, et al. Chronic kidney disease increases atrial fibrillation inducibility: involvement of inflammation, atrial fibrosis, and connexins. Front Physiol. (2018) 9:1726. doi: $10.3389 /$ fphys. 2018.01726

Conflict of Interest Statement: The authors declare that the research was conducted in the absence of any commercial or financial relationships that could be construed as a potential conflict of interest.

Copyright (c) 2019 Zhang, Feng, Leung, Wang and Zhang. This is an open-access article distributed under the terms of the Creative Commons Attribution License (CC $B Y)$. The use, distribution or reproduction in other forums is permitted, provided the original author(s) and the copyright owner(s) are credited and that the original publication in this journal is cited, in accordance with accepted academic practice. No use, distribution or reproduction is permitted which does not comply with these terms. 